\title{
Obituary
}

\section{John Hamer}

- ormer Consultant Cardiologist, St - Bartholomew's Hospital, London. (born London 1927; qualified King's College Hospital 1951; MD, PhD, FRCP), died 6 November 2003.

John Hamer was clearly marked out for a glittering academic career in cardiology. Honours and prizes characterised his student years. After National Service as a junior Specialist in the Royal Army Medical Corps, he took posts in the USA, first in Boston and subsequently in Philadelphia. He returned to the UK, and within four years became Assistant Director of the Institute of Cardiology and Assistant Physician at the National Heart Hospital. His move to Barts in 1965 brought a new dynamism to research within the department of cardiology. John's enthusiasm was infectious, his leadership was inspiring, his encouragement of juniors and associates was greatly appreciated. His warmth of character was enjoyed by both colleagues and patients. His interest was wide, spanning clinical pharmacology, early work on calcium uptake by the sarcoplamsic reticulum, action potentials, body potassium and aldosterone in

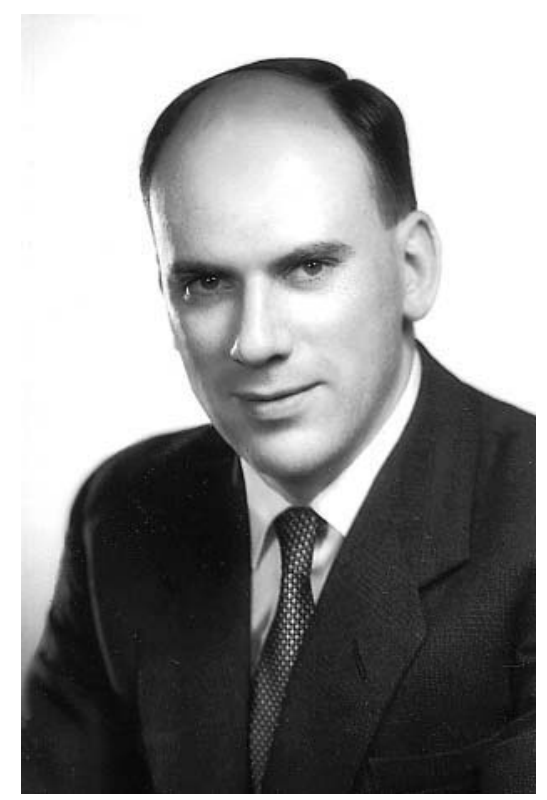

relation to heart disease, and infective endocarditis. In addition to a steady flow of high quality research papers, he contributed to many standard textbooks and edited Recent Advances in Cardiology for several years. He was active in the
British Cardiac Society and became its Secretary. All this productive activity was tragically curtailed when John suffered a left hemiplegia in 1973, which only partially resolved despite his efforts at rehabilitation-so resolute that they were featured on a television programme. John nevertheless continued working part time in the Department of Clinical Pharmacology for 12 more years and attending meetings of the British Cardiac Society. This enabled him to make more contributions to the management of heart disease. He was finally forced into premature retirement by increasing disability. His interest in cardiology remained unabated, but his frustration was mitigated by his enjoyment of a new home in Lyme Regis. That he survived for 30 years after his stroke is a tribute not only to his own determination but also to the devoted care he received from his wife, Ellen. He is also survived by two sons, two daughters, and seven grandchildren.

D Chamberlain, T R D Shaw chambda@pavilion.co.uk 